\title{
PROGRESSIVE HEMIFACIAL ATROPHY (PARRY-ROMBERG SYNDROME)- A CASE REPORT AND REVIEW OF LITERATURE
}

\author{
Jonnalagadda Balachandrudu1, Jonnalagadda Srinivasarao ${ }^{2}$
}

1Assistant Professor, Department of Dermato-Venereology, Sri Venkateswara Medical College, Tirupati, A. P.

${ }_{2}^{2}$ Associate Professor, Department of Microbiology, Sri Pinnamaneni Siddhartha Medical College, Gannavaram, A. P.

HOW TO CITE THIS ARTICLE: Balachandrudu J, Srinivasarao J. Progressive hemifacial atrophy (Parry-Romberg syndrome)- a case report and review of literature. J. Evolution Med. Dent. Sci. 2018;7(08):1063-1064, DOI: 10.14260/jemds/2018/241

\section{PRESENTATION OF CASE}

Hemifacial atrophy, originally described by Parry and Henoch and Romberg ${ }^{1}$ consists of slow progressive atrophy of the soft tissue of essentially half the face which is characterized by progressive wasting of subcutaneous fat, atrophy of skin, cartilage, bone and muscle.1,2 Although, the atrophy is confined to one side of the face and cranium, it may occasionally spread to the neck, one side of the body and is accompanied by usually contralateral Jacksonian epilepsy, trigeminal neuralgia and changes in eyes and hair. The hemifacial atrophy is a form of localized scleroderma that is supported by concurrence of scleroderma. The presence of antinuclear antibodies in serum suggested that ParryRomberg syndrome may be a form of localized scleroderma ${ }^{1-10}$

Lamer and Bennison has also reported discordance in a pair of monozygotic twins. The affected twin was a 42 years old male, Caucasian, who complained of progressive wasting of the left side of his face at age of 17. In addition, there is no bony or cerebral asymmetry in the skull radiographs and CT brain scan respectively. ${ }^{5}$

A case report of hemifacial atrophy and review of literature is presented in this paper.

A variety of treatment techniques have been employed in an attempt to improve the atrophic deformity. These have included free fat grafts, dermis fat grafts, fascia, cartilage and bone for augmentation purposes.

However, when dealing with mild cases of hemifacial atrophy, prostheses are particularly useful, in that facial disproportion could be easily lifted up to an acceptable aesthetic condition.

\section{CASE REPORT}

A 42-year-old male presented with facial asymmetry, progressive wasting of the skin and soft tissue on the left side of face. Skin examination revealed atrophic patch on the left side of forehead extending caudally along the left nasolabial fold and involved right alar cartilage as well, which was hypoplastic leading to narrow nostril. Skin over involved area was smooth, could be easily pinched up on palpation and was not dyspigmented.

'Financial or Other Competing Interest': None.

Submission 13-01-2018, Peer Review 07-02-2018,

Acceptance 12-02-2018, Published 19-02-2018.

Corresponding Author:

Dr. Jonnalagadda Balachandrudu,

C/o. Flat No. 204,

Mullapudi Enclave,

$3^{\text {rd }}$ Line, Kannavarithota, Guntur-522004.

E-mail: jonnalagaddabalu@gmail.com

DOI: $10.14260 /$ jemds $/ 2018 / 241$

\section{(c) $(1)(3)$}

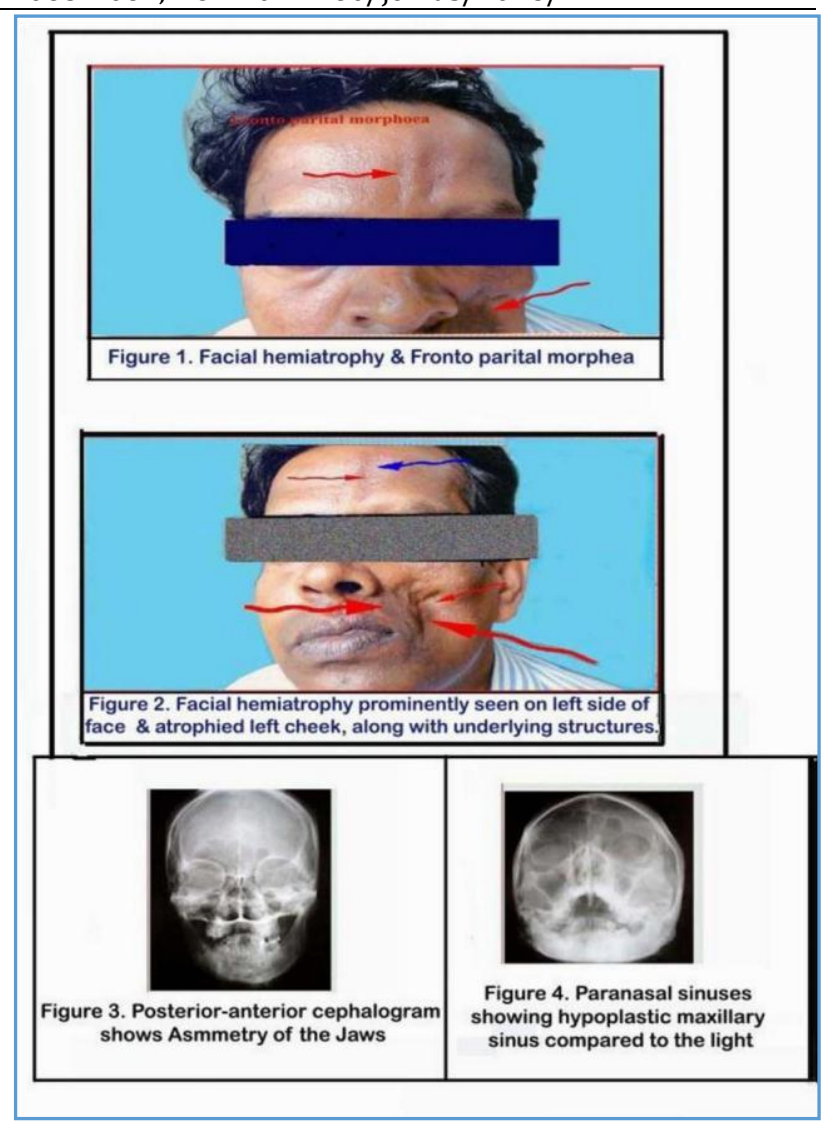

During physical examination, patient presented with facial asymmetry and marked hypoplasia on left side of the face, deviation of lips towards left side of the face, enophthalmos in the left eye region (Fig.2). A big linear scar (coup de sabre) was present on left side passing upwards involving lips, the mandibular mentum and ala of the nose producing obvious deep notching of the upper and lower lip leads to exposure of anterior teeth on the left side (Fig.1). Routine blood investigation, x-ray of skull taken. We kept a differential diagnosis of progressive hemifacial atrophy and linear localised scleroderma (LSC) "en coup de sabre," as both these entities simulate each other. We counselled the patient about the incurable nature of the condition and offered him with these clinical and radiological findings. The diagnosis of progressive hemifacial atrophy was made. At present patient is being periodically reviewed until atrophic manifestations stop and specific intervention could be accomplished.

\section{DISCUSSION}

Progressive hemifacial atrophy as described in the case of above is a rare pathology of unknown cause, whose degenerative condition affects not only aesthetic but also the functionality of the attained hemiface.

The aetiology of hemifacial atrophy has been the subject of numerous theories which include heredity, viral infection, 
trauma, endocrine disturbances, autoimmunity, sympathetic malfunctions, trigeminal neuritis and association with a connective tissue disorder, particularly with scleroderma. A cerebral disturbance on fat metabolism has also been proposed as a primary cause. However, none of the theories withstand thorough investigation and currently the cause of hemifacial atrophy remains unresolved.

A supposed neurotrophic pathogenesis was described by Cassirer in $1912.3^{3-7}$ He proposed that atrophic disease follows the pattern of trigeminal nerve innervations. Certain studies suggest that the disorder was a familial one. The anatomical changes of Parry-Romberg syndrome impact the growth of hard tissue preventing an increase in size during active growth periods. The associated soft tissues shrink by loss of adipose tissue. Atrophy started in second decade of life is less noticeable, because facial growth is nearly complete. Early disease onset and long duration cause greater deformity.

Frequently, the onset of Parry-Romberg syndrome occurs along first and second decades of life. The syndrome seems to have higher incidence among women and affects left side of the face most often. Characteristically, the atrophy progresses slowly over many years and then it becomes stable. Alternatively, the condition may "burn" itself out at a very early stage and results in minimal deformity. The extension of the atrophy is frequently limited to one side of the face and the ipsilateral involvement of body is rare. ${ }^{3-8}$

Clinically, the skin can be dry and with dark pigmentation. Some patients present with a demarcation line between normal and abnormal skin, reminding a big linear scar known as "coup de sabre," as could be noticed in this patient. Ocular involvement is common, and the most frequent manifestation is the enophthalmos, due to fat loss around the orbit as was observed in the present case. The eye usually works normally. There may be localised alopecia observed in present case in the region of left eyebrow. Occasionally, there may be some neurological complications such as trigeminal neuralgia, facial paraesthesia, severe headache and contralateral epilepsy. ${ }^{7}$ These complications were not discerned in the present case. Mouth and nose are deviated to the affected side deviations also facial and dental midlines.

Radiographically, teeth on affected side can present some deficiency in root development and consequently delayed eruption. However, the affected teeth are normal and vital clinically. Very often there is unilateral posterior cross bite as a result of jaw hypoplasia and delayed teeth eruption (Fig. $3,4)$. The intraoral soft tissue and chewing muscle are usually normal without any movement, speech or deglutition implications. Histologically, atrophy of epidermis, dermis and subcutaneous tissue is observed. Variable infiltrate of lymphocytes, monocytes, at dermis and lack of subcutaneous fat in the affected tissue are also characteristic.

Differential diagnoses include hemifacial microsomia (first and second branchial arch syndrome) and its variant such as Goldenhar syndrome, but these are congenital and essentially non-progressive conditions. Post-traumatic atrophy and partial lipodystrophy (Barraquer-Simon Syndrome) are also included in the differential diagnosis. ${ }^{1-8}$ However, partial lipodystrophy is usually bilateral, involves primarily the adipose tissue.

Parry-Romberg Syndrome1-10 is an auto-limitable condition and there is no cure. Affected patient should have multidisciplinary attendance of physicians, dentists, phonoaudiologists and psychologists. The treatment is usually based on reposition of adipose tissue that was lost due to atrophy. Autologous fat grafts, cartilage grafts, silicone injections and prostheses, bovine collagen and inorganic implants, are some alternatives to aesthetic correction of the atrophy. 12 Besides aesthetic improvement, symptomatic treatment of neurological disorders is indicated. The cosmetic treatment is just recommended when the illness stops its evolution, so this is the reason why this patient has not been submitted to any surgical intervention yet.

\section{CONCLUSION}

In conclusion, a case of progressive hemifacial atrophy with its archetypal feature was discussed. Till recently, the exact aetiology and pathogenesis of this degenerative condition have not been elucidated. Many patients present with classic clinical features and there is little intricacy in diagnosis of progressive hemifacial atrophy, still some clinical conditions especially scleroderma should be kept in mind while dealing with this disorder. Proper diagnosis and multidisciplinary treatment approach is essential for management of progressive hemifacial atrophy. ${ }^{1-12}$

\section{REFERENCES}

[1] Pinheiro TP, Silva C, Silveira CS, et al. Progressive hemifacial atrophy--case report. Med Oral Patol Oral Cir Bucal 2006:11(2):E112-4.

[2] Parry-Romberg syndrome. (Last updated on 2009). http://www.whonamedeit.com/doctor.cfm

[3] Whyman RA, Doyle TC, Harding WJ, et al. An unusual case of hemifacial atrophy. Oral Surg Med Oral Pathol 1992;73(5):564-9.

[4] Anderson PJ, Molony D, Haan E, et al. Familial ParryRomberg disease. Int J Pediatr Otorhinolaryngol 2005;69(5):705-8.

[5] Neville BW, Daman DD, Allen CN, et al, eds. Oral maxillofacial pathology. $3^{\text {rd }}$ edn. India: Elsevier Inc 2009:40-1.

[6] Mazzeo N, Fisher, JG, Mayer MH, et al. Progressive hemifacial atrophy (Parry-Romberg syndrome)-case report. Oral Surg Oral Med Oral Pathol Oral Radiol Endod 1995;79(1):30-5.

[7] Colquhoun AN, Ferguson MM, Doyle TC. Hemifacial atrophy with bilateral short roots. Br J Oral Maxillofac Surg 2000;38(5):533-6.

[8] Tollefson MM, Witman PM. En coup de sabre morphea and Parry-Romberg syndrome: a retrospective review of 54 patients. J Am Acd Dermatol 2007;56(2):257-63.

[9] Blaszczyk M, Jablonska S. Linear scleroderma en Coup de sabre. Relationship with progressive facial hemiatrophy (PFH). Adv Exp Med Biol 1999;455:1014.

[10] Sharma M, Bharatha A, Antonyshyn OM, et al. Case 178: Parry-Romberg syndrome. Radiology 2012; 262(2):721-5.

[11] Parry-Romberg. https://www.ninds.nih.gov/Disorders/AllDisorders/Parry-Romberg-information-page NINDS

[12] Roddi R, Riggio E, Gilbert PM, et al. Clinical evaluation of techniques used in surgical treatment of progressive hemifacial atrophy. J Craniomaxillofac Surg 1994;22(1):23-32. 